\title{
Concepções de Gênero nas Narrativas de Adolescentes
}

\author{
Gender Conceptions in Adolescents' Narratives
}

\author{
Gabriela Sagebin Bordini* \& Tania Mara Sperb \\ Universidade Federal do Rio Grande do Sul, Porto Alegre, Brasil
}

\begin{abstract}
Resumo
A adolescência é um período de redefinição das identidades, incluindo a dimensão de gênero. O objetivo do presente estudo foi conhecer as concepções de adolescentes sobre o que é ser homem e ser mulher, a partir de suas próprias narrativas. Participaram 41 adolescentes, com idades entre os 14 e os 15 anos, estudantes de uma escola pública e de uma escola privada de Porto Alegre. Com eles, foram realizados 6 grupos focais on-line síncronos, através do programa de bate-papo MSN: 2 grupos compostos por adolescentes homens, 2 por adolescentes mulheres, e 2 mistos. As narrativas produzidas a partir da interação nos grupos foram analisadas mediante Análise de Conteúdo, que revelou uma predominância dos papéis tradicionais de gênero.

Palavras-chave: Narrativa, gênero, adolescência, grupos focais on-line síncronos.
\end{abstract}

\begin{abstract}
Adolescence implicates redefinition of identity, including gender dimension. The goal of this research was to identify teenagers' conceptions about what it means to be a man and a woman through their own narratives. Forty-one teenagers, between 14 and 15 years old, who were students from a public school and from a private school both located in the city of Porto Alegre/RS, Brazil, participated in the study. Through the MSN chat software, 6 synchronous online focus groups were formed: 2 groups of male adolescents, 2 of female adolescents, and 2 of mixed genders. The narratives produced by the interaction in the groups were analyzed by Content Analysis that revealed a predominance of traditional gender roles.

Keywords: narrative, gender, adolescence, synchronous online focus groups.
\end{abstract}

Gênero é uma construção social e histórica, um conceito dinâmico que se encontra em constante elaboração (Louro, 2007; Scott, 1995). Essa construção permanente torna importante a investigação das atuais concepções acerca do masculino e do feminino. Neste artigo, apresentam-se as concepções de gênero de adolescentes, visto que a adolescência vem sendo representada como um período capaz de expressar aspectos do momento histórico e dos contextos, social e cultural, contemporâneos (Justo, 2005).

Na sociedade ocidental, a adolescência é tida como uma fase, na qual aconteceria a transição entre o mundo infantil e o mundo adulto. Diante dessa concepção e a partir da maturação física e da aquisição de capacidades cognitivas, o adolescente deve realizar uma tarefa principal: "a construção identitária a partir de novos referenciais" (Bremm \& Bisol, 2008, p. 273). Segundo Bremm e Bisol (2008), a adolescência é considerada como o momento de elaboração, por parte do indivíduo, do seu projeto de

\footnotetext{
*Endereço para correspondência: Departamento de Psicologia do Desenvolvimento e da Personalidade, Instituto de Psicologia, Universidade Federal do Rio Grande do Sul, Rua Ramiro Barcelos, 2600, Santana, Porto Alegre, RS, Brasil 90035-003. E-mail: charlestonbordini@yahoo.com.bre sperbt@terra.com.br
}

vida. Para dar conta disso, ele revê os papéis que eram ocupados na infância e busca novos referenciais além da família. Assim, o adolescente construirá novos significados sobre si e sobre o mundo.

Dentre os significados a serem repensados e construídos, inserem-se aqueles atribuídos ao masculino e ao feminino, dado que o gênero é um aspecto importante no desenvolvimento da identidade na adolescência (Oliveira, 2007; Subrahmanyam, Smahel, \& Greenfield, 2006). Segundo Miranda-Ribeiro e Moore (2003), a identidade de gênero é um dos componentes em formação no processo de construção das identidades dos adolescentes, para o qual contribuem decisivamente a família, os pares e a mídia, entre outros.

Nesse processo de construção das identidades, merece destaque o papel da interação social, por permitir a identificação do indivíduo como masculino ou feminino, mediante o contato com os significados referentes ao masculino e ao feminino, presentes na cultura (Diamond, 2002; Louro, 2004). Em uma determinada cultura, existem feminilidades e masculinidades hegemônicas, que estabelecem padrões nos quais se instituem o que é ser homem e o que é ser mulher (Meyer, 2000). Isto é, expectativas e normas que orientam o indivíduo quanto às características, aos comportamentos, às atividades, femininas e masculinas. A heterossexualidade é um exemplo 
disso, sendo um significado comumente associado tanto a ser homem quanto a ser mulher (Latham, 2006; Santos \& Silva, 2008; Sefton, 2006). A força desses significados se deve ao pesado investimento que thes é feito por instituições como família, escola, mídia, lei, que reiteram as identidades e práticas hegemônicas, fortalecendo-as (Louro, 2001).

Considerando-se especificamente as masculinidades hegemônicas, segundo pesquisas realizadas no Brasil (Louro, 2001; Miranda-Ribeiro \& Moore, 2003; Nascimento \& Gomes, 2008; Santos \& Silva, 2008; Seffner, 2008; Sefton, 2006), ser homem tem sido associado ao sucesso profissional, à execução de atividades práticas e de tomadas de decisões, à violência, à força física, à valentia, à capacidade de oferecer segurança e proteção, à paternidade, ao sustento da família, à racionalidade, à competitividade, à potência sexual, à incapacidade de controlar os instintos sexuais. No que tange às feminilidades hegemônicas, há associação entre ser mulher e a beleza, a magreza, a sensualidade, a delicadeza, a docilidade, a obediência, a discrição, o comedimento, a subordinação ao homem, o amor romântico, a monogamia, a maternidade (Friederichs, 2008; Latham, 2006; Louro, 2001; Miranda-Ribeiro \& Moore, 2003; Santos \& Silva, 2008; Sefton, 2006).

Entretanto, por serem fruto de convenções, tais definições sobre ser homem e ser mulher são incompletas, não abarcando a totalidade de significados associados ao masculino e ao feminino (Connel, 1995). Como observa Scott (1995), “'homem' e 'mulher' são, ao mesmo tempo, categorias vazias e transbordantes. Vazias, porque não têm nenhum significado último, transcendente. Transbordantes, porque mesmo quando parecem estar fixadas, ainda contêm dentro delas definições alternativas, negadas ou suprimidas" (p. 93).

Considera-se que tal incompletude das definições hegemônicas sobre ser homem e ser mulher seja resultado do papel ativo do indivíduo na elaboração de significados. Sendo capazes de fazer construções próprias a respeito do masculino e do feminino, os indivíduos contribuem para a elaboração permanente de tais definições e, ao mesmo tempo, para a construção de suas identidades. Nesses processos ressalta-se o papel da narrativa. Conforme explica Bruner (1997), o indivíduo, ao construir histórias e ter contato com as histórias dos outros, dá sentido à sua experiência e à sua realidade. Mais do que isso, narrando, além de o sujeito tentar explicar-se, justificando seus atos e os papéis que desempenha, é possível construir novos significados, bem como posicionar-se em relação aos mesmos (Lopes de Oliveira, 2006). A narrativa aparece, então, como uma importante ferramenta, que permite o acesso aos significados referentes a ser homem e a ser mulher.
Neste trabalho, procurou-se conhecer as concepções de adolescentes sobre o que é ser homem e o que é ser mulher, a partir de suas próprias narrativas, produzidas em interação em um ambiente virtual. Esperava-se que essas concepções assemelhassem-se às definições hegemônicas de gênero identificadas pelas pesquisas supracitadas, embora nenhuma delas tenha trabalhado diretamente com as produções de adolescentes homens e mulheres sobre o tema. Por outro lado, havia também a expectativa de encontrar uma valorização das identidades desviantes - a saber, aquelas não associadas aos valores dominantes -, já que a adolescência é considerada como um período de questionamentos e ressignificações identitárias (Bremm \& Bisol, 2008).

\section{Método}

\section{Participantes}

Participaram da pesquisa 41 adolescentes, com idades entre 14 e 15 anos. Os participantes foram selecionados por conveniência, sendo 20 deles alunos de uma escola privada de Porto Alegre e 21, alunos de uma escola pública da mesma cidade. Os participantes eram de diferentes estratos sociais, de acordo com critérios baseados em Hollingshead (1975). Para fins de análise, foram utilizados dois grupos - o da escola pública e o da escola privada -, já que estudos na área da adolescência têm usado tal modelo comparativo, por considerarem que o tipo de escola frequentado implica, no Brasil, diferenças culturais e socioeconômicas (Carlini-Cotrim, Gazal-Carvalho, \& Gouveia, 2000).

\section{Delineamento, Procedimentos e Instrumentos}

O projeto de pesquisa foi aprovado pelo Comitê de Ética em Pesquisa do Instituto de Psicologia da Universidade Federal do Rio Grande do Sul (Projeto no 2008/093). Utilizouse um delineamento qualitativo, de caráter exploratório, para conhecer as concepções dos adolescentes sobre o que é ser homem e o que é ser mulher, a partir de suas próprias narrativas. Foram convidados a participar do estudo todos os alunos do primeiro ano do Ensino Médio de uma escola pública e de uma escola privada. Adicionalmente, foram convidadas alunas de uma turma de oitava série do Ensino Fundamental da escola privada. Depois que todos os interessados em participar da pesquisa e seus responsáveis assinaram os Termos de Consentimento Livre e Esclarecido, os adolescentes foram divididos em grupos.

Em cada escola formaram-se três grupos: um misto (sete adolescentes), um com sete adolescentes homens e outro com sete adolescentes mulheres (seis, no caso da escola privada). Cada grupo reuniu-se uma única vez na sala de informática das escolas, para a realização do grupo focal on-line síncrono; isto é, uma discussão moderada pela pesquisadora, executada através do programa de bate-papo Windows Live Messenger (MSN), que permite conversar em tempo real, via internet. Cada participante, bem como a moderadora, tinha um computador conectado ao MSN à sua disposição. Após todos terem escolhido um pseudônimo virtual, a pesquisadora alertava 
que não era mais permitido interagir oralmente e lançava a questão: "Queria que vocês contassem histórias ou situações que mostram bem o que é ser homem ou o que é ser mulher hoje". Toda a conversa era feita por escrito e era gravada e transformada em um arquivo de texto pelo próprio MSN. As discussões duraram cerca de uma hora.

\section{Resultados e Discussão}

A interação do grupo propiciou a elaboração conjunta de narrativas, que eram, em geral, fragmentadas, curtas e entrecortadas por outros assuntos. Tais narrativas poderiam ser classificadas como "pequenas histórias", pois não correspondiam às narrativas tipicamente obtidas em pesquisas, tratando-se, algumas vezes, de contações de eventos futuros, hipotéticos ou compartilhados, como descreveu Georgakopoulou (2007). Essas particularidades foram atribuídas à realização on-line dos grupos focais. Nesses, os participantes fazem comentários mais curtos e menos elaborados e emitem frases menores, em comparação com os grupos presenciais (Schneider, Kerwin, Frechtling, \& Vivari, 2002).

Todas as narrativas foram submetidas à Análise de Conteúdo (cf. Bardin, 1977/2008). A unidade de análise foi a narrativa, reconhecida cada vez em que era feita menção à ocorrência de uma sequência de eventos, envolvendo seres humanos como personagens ou autores, que indicasse que algo aconteceu (Bruner, 1986/1998). As narrativas foram lidas exaustivamente e, então, classificadas a partir do critério semântico. Isto é, identificou-se o tema do acontecimento central relatado em cada narrativa, embora temas secundários pudessem estar presentes. Em seguida, as narrativas cuja temática era semelhante foram agrupadas na mesma categoria. As categorias eram mutuamente excludentes. Subcategorias foram identificadas em uma dessas categorias. O número de narrativas classificadas em cada categoria e subcategoria foi contabilizado.

De um total de 60 narrativas coletadas, os alunos da escola privada foram responsáveis por $32 \mathrm{e}$, os da escola pública, por 28. Essas narrativas foram classificadas nas seguintes categorias: Atributos físicos característicos, Assimetria nas relações de gênero, Responsabilidade com a família e Sexualidade, esta última, composta por seis subcategorias (Hipossexualização da mulher, Hipersexualização do homem, Homossexualidade, A desilusão da primeira vez, Pedofilia e Amizade versus Sexualidade). A seguir, apresenta-se cada uma das categorias e subcategorias, sempre as descrevendo por meio de um texto-síntese e discutindo os resultados à luz da literatura. Devido à preponderância da categoria Sexualidade, as subcategorias que a compõem são descritas mais detalhadamente, incluindo a apresentação de narrativas ilustrativas das subcategorias mais numerosas.

\section{Atributos Físicos Característicos}

Diz respeito à diferenciação entre homens e mulheres baseada em características físicas. Três narrativas foram aqui categorizadas, todas produzidas pelos adolescentes da escola privada. Uma dessas narrativas tratava da associação entre ser homem e as características de força física, resistência à dor e coragem. As outras duas referiam-se à relação entre a mulher e a beleza física, no sentido de cuidados e vaidades em relação ao próprio corpo. Essa diferenciação entre homens e mulheres baseada em características físicas ocorre na maioria das culturas, de acordo com Nicholson (2000). Segundo a autora, a divisão binária entre corpo masculino e corpo feminino reduz os sentidos atribuídos às mulheres e aos homens, como se existissem um homem e uma mulher únicos - que aqui se traduziriam no homem macho e na mulher bonita.

\section{Assimetria nas Relações de Gênero}

Trata da assimetria nas relações entre homens e mulheres. Aqui foram categorizadas cinco narrativas, também essas produzidas unicamente pelos participantes da escola privada. Tais narrativas apresentavam personagens homens que tomavam as relações entre homens e mulheres como assimétricas, e personagens mulheres que aceitavam ou questionavam essa desigualdade. Uma delas, por exemplo, referia-se a uma mulher que abdicou dos estudos por exigência do marido; outra relatava uma situação em que uma mulher fez questão de dividir uma despesa com um homem. Esses dados vão ao encontro dos resultados da investigação realizada por Latham (2006) sobre webpages construídas por mulheres. A pesquisadora também encontrou indícios tanto de subordinação da mulher ao homem, quanto de resistência feminina a esse modelo de subordinação e de luta pela igualdade de direitos entre os gêneros.

\section{Responsabilidade com a Família}

Diz respeito à responsabilidade do indivíduo em relação à sua família, na função de genitor. São narrativas que se referiam à responsabilidade da mulher, do homem ou de ambos com a sua família, na função de mãe e de pai. Essas narrativas foram produzidas nos dois contextos, ainda que em números diferentes na escola pública e na escola privada (oito e duas narrativas, respectivamente).

$\mathrm{Na}$ escola pública, essa foi a segunda categoria mais frequente. Oito narrativas foram elaboradas pelo grupo de adolescentes homens e pelo grupo misto. Todas incluíam uma mulher no papel de mãe responsável, que trabalha e se sacrifica para cuidar da família, por vezes sem poder contar com ninguém. Três delas, além disso, traziam um personagem homem que aparecia no papel de responsável pela sua família - por exemplo, engravidando uma garota e assumindo o filho. Duas narrativas apresentaram um personagem homem irresponsável em re- 
lação à sua família, abandonando-a ou não a ajudando financeiramente.

Enquanto isso, na escola privada, apenas duas narrativas foram aqui categorizadas. Uma delas, produzida pelo grupo de adolescentes homens, referia-se à responsabilidade da mulher e do homem com a sua família, na função de mãe e de pai. A outra narrativa foi contada pelo grupo de adolescentes mulheres e trazia um personagem homem irresponsável, abandonando a namorada depois de engravidá-la.

A presença dessas narrativas confirma o quanto a responsabilidade - tanto do homem, quanto da mulher - para com a família faz parte do ideário de uma masculinidade e de uma feminilidade prototípicas (Friederichs, 2008; Nascimento \& Gomes, 2008). Por outro lado, a atitude irresponsável em relação à família chama atenção por ter sido associada apenas ao homem. A elaboração de narrativas relacionadas à irresponsabilidade paterna pode indicar que esse tipo de comportamento esteja, atualmente, incluído nos significados referentes à masculinidade hegemônica.

A diferença quanto ao número de narrativas classificadas na categoria Responsabilidade com a família, na escola pública e na escola privada (oito e dois, respectivamente), pode estar relacionada ao contexto familiar dos participantes. Oliveira (2007) destacou o papel da família como agente de socialização para o jovem. É possível que os adolescentes da escola pública tenham crescido em ambientes familiares nos quais as identidades e papéis de gênero tradicionais tenham sido bastante enfatizados, conforme explica a autora. Sabe-se que, sobretudo em condições de precariedade social, os homens são socializados pela família para o sustento da casa e para a independência econômica (Souza, 2008). Nascimento e Gomes (2008), por exemplo, encontraram que adolescentes moradores de comunidades de baixa renda relacionavam ser homem a ser provedor da família. Já a mulher vem sendo associada à maternidade $\mathrm{e}$ aos cuidados com os filhos (Latham, 2006). É provável, então, que os participantes da escola pública provenham de ambientes que enfatizam os modelos típicos de paternidade e de maternidade. Assim, tanto a correspondência, quanto a não correspondência a esse padrão chamariam a atenção desses adolescentes, fazendo com que fosse produzido um maior número de narrativas.

\section{Sexualidade}

Aqui foram agrupadas as subcategorias que se relacionavam com a temática da sexualidade. Do total de 60 narrativas produzidas por todos os grupos focais, 42 versaram sobre algum tema relativo à sexualidade. Como os resultados provenientes dos dados dos alunos da escola pública e da escola privada mostraram diferenças entre si, estes são apresentados separadamente.

As Narrativas dos Adolescentes da Escola Pública. A Tabela 1 mostra as subcategorias agrupadas por se relacionarem com a temática da sexualidade.

Tabela 1

Distribuição das Narrativas da Escola Pública na Categoria "Sexualidade”, por Grupo e por Subcategoria

\begin{tabular}{lcccc}
\hline Subcategorias & Mulheres & Homens & Misto & Total \\
\hline Hipossexualização da mulher & 05 & 02 & & 07 \\
Hipersexualização do homem & & 03 & 03 & 06 \\
Homossexualidade & 03 & 03 & & 03 \\
A desilusão da primeira vez & & & 01 & 03 \\
Pedofilia & 08 & 08 & 04 & 20 \\
\hline Total & & & 04
\end{tabular}

Para a sua análise, apresentam-se, a seguir, exemplos de narrativas classificadas nas subcategorias de maior ocorrência, da maneira como foram transcritas pelo MSN. Os exemplos são narrativas que foram recortadas das interações originais. Isto é, os outros assuntos que se intercalavam com as narrativas foram excluídos. As exclusões são indicadas por “_ _ _, para diferenciar dos “...”, utilizados pelos próprios participantes. Os pseudônimos utilizados pelos participantes foram substituídos por números, com o objetivo de manter o seu anonimato.

Hipossexualização da Mulher. Diz respeito à associação entre ser mulher e ser heterossexual e pouco sexualizada. A maioria das narrativas aqui categoriza- das foi produzida pelo grupo de adolescentes mulheres. Tais narrativas tratavam principalmente da adolescente que assume uma posição ativa em relação à própria sexualidade, expressando-a livremente, e por isso fica mal falada no grupo de pares (é chamada de vadia, por exemplo). Também foram aqui categorizadas as narrativas que apontavam para um incentivo ao comportamento pouco sexualizado da mulher, como por exemplo, a situação em que uma adolescente que se coloca na posição de ser difícil de conquistar por um adolescente torna-se atraente. Essa subcategoria refere-se, então, à desvalorização social da sexualidade feminina e do posicionamento ativo da mulher, bem como à hegemonia da heterossexualidade. 
O Exemplo 1 mostra alguns desses aspectos.

Exemplo 1 (trecho de narrativa produzida no grupo de adolescentes mulheres):

$---$

Participante 1:

tinha uma mina aii qe eu conec

qe ela fikava até com gurii de 11 anos

$---$

Participante 1:

no meu aniversário ela fiko com 5 gurii

ela comec a ama um gurii

Pesquisadora:

e ai?

Participante 1:

qandu ela amo o gurii não qis namora com ela mais pq ela era muito puta a

Hipersexualização do Homem. Trata da relação entre ser homem e ter uma heterossexualidade exacerbada. Tanto o grupo misto, quanto o grupo de adolescentes homens produziram narrativas aqui categorizadas. Essas abordavam a aceitação da traição como atributo masculino e a aceitação ou até o estímulo à promiscuidade, considerada um comportamento próprio do homem e incontrolável. A promiscuidade apareceu como um atributo tão importante que a sua ausência era condenada pelo grupo de pares, algumas vezes por meio da associação com a homossexualidade. Essas narrativas revelam a preponderância da heterossexualidade e a forte relação entre masculinidade e sexualidade. Isso pode ser percebido no Exemplo 2.

Exemplo 2 (trecho de narrativa produzida no grupo de adolescentes homens):

Participante 4:

porque tipo,tem um monte de mina no coolegio, e ele

é gay e não pega ninguém, e uma

ainda pediu e ele nego é mttt gay

Pesquisadora:

uma ainda pediu? como assim?

Participante 4:

a mina chega e pedi e ele nega, isso é mt gay
Homossexualidade. Diz respeito às características do homem homossexual e dos valores que lhe são atribuídos. Essa subcategoria apareceu como uma exclusividade do grupo de adolescentes homens. Englobou narrativas de situações de preconceito em relação a homens homossexuais ou transexuais, incluindo, a associação desses homens à bizarrice e à anormalidade.

A Desilusão da Primeira Vez. Trata da desilusão da mulher quanto ao parceiro ou ao relacionamento, após perder a virgindade. Essa subcategoria apareceu como uma exclusividade do grupo de adolescentes mulheres. São narrativas que envolviam personagens adolescentes iludidas quanto ao parceiro ou ao relacionamento, que se desiludiam ao serem abandonadas pelo namorado depois de perder a virgindade. Tais ilusão e desilusão são visíveis no Exemplo 3.

Exemplo 3 (trecho de narrativa produzida no grupo de adolescentes mulheres):

Participante 1:

Minha amiga essa ela namoro 3 meses e se juravam amor eterno,ele tranzo com ela e

depois termino o namoroo com ela

$---$

Participante 2:

ele comeu ela depois deu um fora nela

Participante 1:

e ela fiko trii mal

Participante 3:

ela era virgem ${ }^{\wedge}$ ?

Participante 1:

ela perdeu a virgindade com ele!

Pedofilia. Aborda a pedofilia na sexualidade do homem. Aqui foi categorizada apenas uma narrativa, que parece ter sido produzida em resposta a um acontecimento muito recente no momento da realização do grupo focal (morte do astro pop Michael Jackson). Em tal narrativa, ser homem estava associado a ser pedófilo.

As Narrativas dos Adolescentes da Escola Privada. A Tabela 2 mostra as subcategorias agrupadas por se relacionarem com a temática da sexualidade.

Tabela 2

Distribuição das Narrativas da Escola Privada na Categoria "Sexualidade”, por Grupo e por Subcategoria

\begin{tabular}{lcccc}
\hline Subcategorias & Mulheres & Homens & Misto & Total \\
\hline Hipossexualização da mulher & & 07 & 02 & 09 \\
Hipersexualizaçao do homem & 03 & 02 & 02 & 07 \\
Homossexualidade & 05 & 01 & & 01 \\
Amizade versus Sexualidade & 08 & 10 & 04 & 22 \\
\hline Total & & & & 05 \\
\hline
\end{tabular}

A seguir, analisa-se cada subcategoria.

Hipossexualização da Mulher. Diz respeito à associação entre ser mulher e ser heterossexual e pouco se- xualizada. Quase todas as narrativas aqui categorizadas foram produzidas pelo grupo de adolescentes homens. Todas tratavam da censura à promiscuidade feminina $\mathrm{e}$ 
da repressão sofrida pelas mulheres quando da expressão de sua sexualidade. $\mathrm{O}$ grupo misto elaborou narrativas em que as adolescentes ficavam mal faladas no grupo de pares por não serem discretas e difíceis de conquistar. Já o grupo de adolescentes homens narrou situações em que, diante da sexualidade da filha mulher, o pai fica brabo e a mãe assustada, irritada, nervosa e preocupada. O Exemplo 4 mostra alguns desses aspectos.

Exemplo 4 (trecho de narrativa produzida no grupo de adolescentes homens):

Participante 5:

tem pai que faz festa quando filho perde virgindade

Participante 5:

agora chega uma menina pra contar pro pai...

bom

nem conto o fim da historia...

era uma vez uma filha...

Participante 6:

o pai fik puto e quase dsa na guria

Participante 5:

a moral é que a vida sexual é mt mais facil pra um homem do que pra uma mulher

infelizmente

Hipersexualização do Homem. Trata da relação entre ser homem e ter uma heterossexualidade exacerbada. Todos os grupos da escola privada produziram narrativas aqui categorizadas. Essas tratavam da aceitação ou até do estímulo à sexualidade do homem. Isto é, a sexualidade aparece como um atributo masculino tão importante que a sua presença é estimulada, valorizando-se a promiscuidade, e a sua ausência é condenada, censurando-se a virgindade. Isso ocorre tanto no grupo de pares (conforme narrativas do grupo de adolescentes mulheres e misto), quanto na família (de acordo com o grupo de adolescentes homens). As narrativas abordaram, por exemplo, situações em que um homem é promíscuo para se vangloriar para os amigos, ou em que a vida sexual ativa do filho é aceita pela família e motivo de orgulho paterno. O Exemplo 5 ilustra o estímulo à sexualidade $\mathrm{e}$ a repressão à virgindade.

Exemplo 5 (trecho de narrativa produzida no grupo de adolescentes misto):

Participante 7:

ela falo que tiraria o cabaço dele

pra todo mundo

so q ele é mongolão

e nao comeu

Participante 8:

fico quieto eu acho

Pesquisadora:

e os outros que tavam ali? como reagiram?

Participante 7:

xingando ele pq ele nao comeu

q ele era um cabaço

Homossexualidade. Diz respeito às características do homem homossexual. Aqui foi categorizada apenas uma narrativa, em que ser um homem homossexual estava associado a ser uma mulher. Os significados atribuídos ao homem e à mulher apareceram de forma rígida. A feminilidade, por exemplo, foi associada a comportamentos como rebolar e olhar para o corpo dos homens.

Amizade versus Sexualidade. Aborda a deslealdade feminina em relação às amigas, quando um homem interessante está em jogo. Essa subcategoria apareceu como uma exclusividade do grupo de adolescentes mulheres. São narrativas que, na sua maioria, apresentavam um enredo no qual uma adolescente é traída por uma amiga, que opta por se relacionar com alguém de quem a outra gostava, ignorando seus sentimentos. Ou seja, a relação a dois é tida como tão importante, que, se preciso for, as adolescentes são desleais às amigas, como mostra o Exemplo 6.

Exemplo 6 (trecho de narrativa produzida no grupo de adolescentes mulheres):

Participante 9:

sei lá, eu to com um cara amiga minha encontrou ele numa festa

e ficou com ele... e ainda teve a cara de pau de me liga e dizer que ele estava na festa,

sozinho... eu acho que uma amiga de verdade não faria isso

As narrativas referentes à sexualidade predominaram em ambos os contextos. Isso condiz com o momento vivido por esses participantes, no qual assumem grande importância a vida sexual e a vida reprodutiva (ECOS Comunicação em Sexualidade [ECOS], 2004). As concepções sobre ser homem e ser mulher foram semelhantes nas narrativas produzidas nas duas escolas: a heterossexualidade explícita e a ênfase na sexualidade ativa foram associadas a ser homem; já a repressão à expressão da sexualidade foi associada a ser mulher.

A subcategoria Hipossexualização da mulher, por exemplo, apontou para a relação entre ser mulher e algumas características encontradas na literatura, como ser discreta, só ficar com um menino por vez (MirandaRibeiro \& Moore, 2003) e ser heterossexual (Latham, 2006). As narrativas categorizadas em A desilusão da primeira vez e em Amizade versus Sexualidade vão ao encontro desse resultado. Todas essas subcategorias mostraram que, ainda hoje, o amor romântico e os relacionamentos duradouros e monogâmicos são relacionados à feminilidade, conforme Santos e Silva (2008) já haviam assinalado.

Já a subcategoria Hipersexualização do homem confirmou que a potência sexual é um componente da masculinidade (Seffner, 2008). Essa potência, contudo, deve seguir uma orientação heterossexual, segundo as narrativas da subcategoria Homossexualidade. Ao apresentarem a homossexualidade e a transexualidade de modo 
depreciativo, os participantes excluíam-nas das suas concepções sobre ser homem. Como explica Louro (2001), a masculinidade tida como normal não é construída unicamente pela sua contraposição à feminilidade, mas também pela contraposição a outras formas de masculinidade.

Essas fixações quanto ao que é ser homem e ser mulher limitam o espectro de significados possíveis de masculinidade e feminilidade, promovendo a dominância de alguns deles (Scott, 1995). De fato, os resultados mostraram a presença de estereótipos nas narrativas dos participantes, fixando os significados referentes à masculinidade e à feminilidade. Isso indica uma reprodução por parte dos adolescentes de padrões sexistas de socialização.

Tais padrões sexistas foram revelados nas narrativas da escola privada. Segundo estas, os estereótipos de masculinidade e feminilidade parecem persistir atualmente graças ao papel do grupo de pares e da família na socialização do adolescente. Quanto à influência dos pares, as narrativas expuseram a competição entre os adolescentes homens pela precocidade sexual e promiscuidade. De acordo com Louro (2001), a competitividade é uma das características mais reforçadas na formação masculina. Quanto à família, as narrativas mostraram-na promovendo uma socialização de gênero padronizada para os adolescentes, fixando características que associam a mulher a um ser pouco sexualizado e o homem a um ser sexualmente ativo. Confirmou-se, assim, o seu papel fundamental como agente de socialização (Oliveira, 2007).

\section{Discussão Geral}

Os resultados mostraram algumas diferenças entre os dois contextos quanto às concepções dos adolescentes sobre ser homem e ser mulher. Na escola privada, os temas das narrativas foram mais variados, o que se percebe pelo maior número de categorias. Na escola pública, por outro lado, as narrativas sobre ser homem e ser mulher se resumiram aos temas da responsabilidade com a família e da sexualidade. Isso indica uma maior amplitude temática nas narrativas da escola privada.

Houve também diferenças, entre as escolas, quanto aos grupos que foram responsáveis pela produção da maior parte das narrativas classificadas em determinadas categorias e subcategorias. Na escola pública, os grupos de adolescentes homens e misto produziram narrativas categorizadas em Hipersexualização do homem, e o grupo de adolescentes mulheres elaborou aquelas categorizadas em Hipossexualização da mulher. Ao contrário, na escola privada, muitas das narrativas categorizadas em Hipersexualização do homem foram formuladas pelo grupo de adolescentes mulheres, e as categorizadas em Hipossexualização da mulher, pelos grupos de adolescentes homens e misto.

Isso mostra que as concepções dos adolescentes da escola pública sobre ser homem e ser mulher estiveram mais relacionadas à sua própria identidade de gênero, já que adolescentes homens narraram sobre o que é ser homem e adolescentes mulheres narraram sobre o que é ser mulher. Os da escola privada, por outro lado, produziram narrativas mais variadas. Além disso, as concepções dos adolescentes da escola pública não apresentaram menor variabilidade somente quanto ao tema da sexualidade. Esses adolescentes também associaram rigidamente ser mulher a ser uma mãe responsável, por exemplo.

Essas diferenças podem estar relacionadas a particularidades dos contextos em que estão inseridos os adolescentes da escola pública e da escola privada. TraversoYépez e Pinheiro (2005) explicam que a socialização de gênero é um processo permanente, que se intensifica nos espaços de convivência cotidiana, diferentes nas duas escolas. Assim, embora não se tenha considerado que os participantes das duas escolas formassem dois grupos uniformes, o conjunto de alunos da escola pública e o conjunto da escola privada apresentaram especificidades quanto às concepções sobre ser homem e ser mulher.

No entanto, ainda que tenham sido identificadas diferenças, a análise de conteúdo das narrativas formuladas nos grupos focais on-line síncronos revelou que muitas das concepções sobre o que é ser homem e o que é ser mulher foram semelhantes nos dois contextos, sobretudo aquelas relacionadas à sexualidade. A prevalência de narrativas classificadas nas subcategorias agrupadas na categoria Sexualidade evidenciou que, para esses participantes, ser homem é se relacionar de determinada forma com mulheres e que ser mulher é se relacionar de determinada forma com homens. Isso não surpreende, já que a sexualidade é um dos aspectos que ganha destaque na adolescência (ECOS, 2004; Subrahmanyam et al., 2006).

A preponderância das narrativas sobre o relacionamento entre homens e mulheres expôs o quanto, ainda hoje, as concepções sobre o masculino e o feminino são delimitadas pelo padrão hegemônico da sexualidade binária e heterossexual, conforme explicou Butler (2003). O domínio da heterossexualidade como significado associado a ser homem e a ser mulher reduz o espectro de outras associações possíveis, reforçando a ideia de uma essência feminina/masculina e de uma oposição natural entre ambas (Scott, 1995).

Isso é visível nas narrativas que abordaram o relacionamento entre homens e mulheres, já que nessas, o homem e a mulher assumiam posições complementares ao se relacionarem. Os homens eram hipersexualizados, as mulheres hipossexualizadas; o posicionamento contrário provocava consequências negativas para o indivíduo. A mulher que expressava ativamente sua sexualidade e o homem que era pouco sexualizado sofriam sanções por parte dos pares e dos pais. Esses resultados revelam que a hipersexualização do homem e a hipossexualização da mulher são duas faces de uma mesma moeda, ressaltando que o binarismo ainda é uma característica do conceito de gênero, como apontado por Scott (1995). 
Bordini, G. S. \& Sperb, T. M. (2012). Concepções de Gênero nas Narrativas de Adolescentes.

\section{Considerações Finais}

O trabalho com participantes com idades entre os $14 \mathrm{e}$ os 15 anos permitiu o acesso aos estereótipos, presentes na cultura, relativos ao homem e à mulher, uma vez que 0 gênero é mais um dos aspectos da identidade que está em desenvolvimento na adolescência (Oliveira, 2007; Subrahmanyam et al., 2006). A presença de tantos estereótipos nas narrativas dos participantes corroborou os resultados de Crouter, Whiteman, McHale, e Osgood (2007), que revelaram que, dos 13 aos 15 anos, ocorre uma estabilização nas atitudes dos jovens acerca dos papéis das mulheres, após uma flexibilização das mesmas entre sete e 13 anos.

De fato, as narrativas produzidas nos grupos realizados associaram o feminino e o masculino, em geral, aos atributos relativos à feminilidade e à masculinidade hegemônicas. Butler (2003) explica que as identidades hegemônicas são sempre acompanhadas por outras identidades não associadas aos valores dominantes. Justamente por isso, o discurso hegemônico é constantemente reforçado, na tentativa de evitar a conquista de espaço por parte dos discursos desviantes, o que prejudicaria a fixação de uma identidade definitiva (Sabat, 2004). A repetição dos estereótipos de gênero, observada nas narrativas coletadas, indica a tentativa de potencialização do discurso hegemônico, motivada possivelmente pela busca, por parte dos adolescentes, pela definição de uma identidade de gênero única e fixa.

É provável, então, que o trabalho com participantes dessa faixa etária tenha dificultado o acesso às concepções sobre ser homem e sobre ser mulher que se desviam do padrão hegemônico de gênero. Ainda que os adolescentes da escola privada tenham demonstrado uma maior variabilidade nas suas concepções de gênero, eles, assim como os participantes da escola pública, reproduziram as narrativas convencionais, ou seja, as definições daquilo que é esperado dos indivíduos em uma dada cultura (Connel, 1995). Diante disso, seria interessante que pesquisas futuras trabalhassem com uma amostra mais ampla em termos de idade.

Por fim, ressalta-se o importante papel que a narrativa produzida em interação pode ocupar como uma ferramenta contra o essencialismo nas questões de gênero. As narrativas elaboradas nos grupos mistos realizados, por exemplo, em geral, trouxeram generalizações sobre as mulheres e os homens. Colocando homens e mulheres uns diante dos outros, um moderador que atuasse como facilitador da relativização das ideias dos participantes poderia fomentar um debate acerca das posições em que eles se colocam e colocam os outros.

\section{Referências}

Bardin, L. (2008). Análise de conteúdo. Lisboa, Portugal: Edições 70. (Original work published 1977)
Bremm, E. S., \& Bisol, C. A. (2008). Sinalizando a adolescência: Narrativas de adolescentes surdos. Psicologia: Ciência e Profissão, 28(2), 272-287.

Bruner, J. S. (1997). Atos de significação. Porto Alegre, RS: Artes Médicas.

Bruner, J. S. (1998). Realidade mental, mundos possíveis (M. A. Domingues, Trad.). Porto Alegre. RS: Artes Médicas. (Original work published 1986)

Butler, J. P. (2003). Problemas de gênero: Feminismo e subversão da identidade (R. Aguiar, Trad.) Rio de Janeiro, RJ: Civilização Brasileira.

Carlini-Cotrim, B., Gazal-Carvalho, C., \& Gouveia, N. (2000). Comportamentos de saúde entre jovens estudantes das redes pública e privada da área metropolitana do Estado de São Paulo. Revista de Saúde Pública, 34(6), 636-645.

Connel, R. W. (1995). Políticas da masculinidade. Educação e Realidade, 20(2), 185-206.

Crouter, A. C., Whiteman, S. D., McHale, S. M., \& Osgood, D. W. (2007). Development of gender attitude traditionality across middle childhood and adolescence. Child Development, 78(3), 911-926.

Diamond, M. (2002). Sex and gender are different: Sexual identity and gender identity are different. Clinical Child Psychology and Psychiatry, 7(3), 320-334.

ECOS - Comunicação em Sexualidade. (2004). Gravidez de adolescentes entre 10 e 14 anos e vulnerabilidade social: Estudo exploratório em 5 capitais. São Paulo, SP: Autor.

Friederichs, M. C. (2008). Corpos escritos na internet: Representações do corpo em blogs. Retrieved July 15, 2010, from http://www.fazendogenero8.ufsc.br/sts/ST53/Marta Cristina_Friederichs_53.pdf

Georgakopoulou, A. (2007). Thinking big with small stories in narrative and identity analysis. In M. Bamberg (Ed.), Narrative - State of the Art (pp. 145-154). Amsterdam, PA: John Benjamins.

Hollingshead, A. B. (1975). Four-factor Index of Social Status Unpublished manuscript, Yale University, New Haven, CT.

Justo, J. S. (2005). O "ficar" na adolescência e paradigmas de relacionamento amoroso da contemporaneidade. Revista do Departamento de Psicologia (UFF), 17(1), 61-77.

Latham, E. E. M. (2006). Linguagem, identidade e gênero na comunicação mediada por computador: Um estudo de webpages pessoais de mulheres. (Tese de Doutorado nãopublicada). Programa de Pós-Graduação em Lingüística, Universidade Estadual de Campinas, SP.

Lopes de Oliveira, M. C. S. (2006). Identidade, narrativa e desenvolvimento da adolescência: Uma revisão crítica. Psicologia em Estudo, 11(2), 427-436.

Louro, G. L. (2001). Currículo, gênero e sexualidade. Porto, Portugal: Porto Editora.

Louro, G. L. (2004). Gênero, sexualidade e educação: Uma perspectiva pós-estruturalista (7. ed.). Petrópolis, RJ: Vozes.

Louro, G. L. (2007). Gênero, sexualidade e educação: Das afinidades políticas às tensões teórico-metodológicas. Educação em Revista, 46, 201-218.

Meyer, D. E. E. (2000). Cultura teuto-brasileiro-evangélica: Articulando gênero com raça, classe, nação e religião. Educação e Realidade, 25(1), 135-161.

Miranda-Ribeiro, P., \& Moore, A. (2003). Papéis de gênero e gênero no papel: Uma análise de conteúdo da Revista Capricho, 2001-2002. Belo Horizonte, MG: Editora da Universidade Federal de Minas Gerais. 
Nascimento, E. F., \& Gomes, R. (2008). Marcas identitárias masculinas e a saúde de homens jovens. Cadernos de Saúde Pública, 24(7), 1556-1564.

Nicholson, L. (2000). Interpretando o gênero. Estudos Feministas, 8(2), 9-41.

Oliveira, E. R. B. (2007). Sexualidade, maternidade e gênero: Experiências de socialização de mulheres jovens de extratos populares. (Dissertação de Mestrado não-publicada). Programa de Pós-Graduação em Educação, Universidade de São Paulo, SP.

Sabat, R. (2004). Só as bem quietinhas vão casar. In D. Meyer \& R. Soares (Eds.), Corpo, gênero e sexualidade (pp. 95106). Porto Alegre, RS: Mediação.

Santos, D. B., \& Silva, R. C. (2008). Sexualidade e normas de gênero em revistas para adolescentes brasileiros. Saúde e Sociedade, 17(2), 22-34.

Schneider, S., Kerwin, J., Frechtling, J., \& Vivari, B. (2002). Characteristics of the discussion in online and face-to-face focus groups. Social Science Computer Review, 20(1), 31-42.

Scott, J. (1995). Gênero: Uma categoria útil de análise histórica. Educação e Realidade, 20(2), 71-99.

Seffner, F. (2008). Homens = sexo, violência e poder: Dá para mudar esta equação? Salto para o Futuro (Brasília), 18(26), 15-19.

Sefton, A. P. (2006). Pai não é de uso diário? Paternidades na literatura infanto-juvenil. (Dissertação de Mestrado não-publicada). Programa de Pós-Graduação em Educação, Universidade Federal do Rio Grande do Sul, Porto Alegre, RS.

Souza, S. D. de. (2008). Educação, trabalho e socialização de gênero: Quando ser mulher pesa mais na balança da desigualdade social. Educação \& Linguagem, 11(18), 170-185.

Subrahmanyam, K., Smahel, D., \& Greenfield, P. (2006). Connecting developmental constructions to the internet: Identity presentation and sexual exploration in online teen chat rooms. Developmental Psychology, 42(3) 395-406.

Traverso-Yépez, M. A., \& Pinheiro, V. S. (2005). Socialização e gênero e adolescência. Revista de Estudos Feministas, 13(1),

\section{Errata}

Bordini, G. S. \& Speb, T. M. (2012). Concepções de Gênero nas Narrativas de Adolescentes. Psicologia: Reflexão e Crítica, 25(4), 738-746.

No artigo acima, o nome do segundo autor é Sperb, T. M. 